\title{
Fracture Mechanism of Ferritic Ductile Iron under Instrumented Impact Load at Low Temperatures
}

\author{
Xinning ZHANG, ${ }^{*}$ Yingdong QU and Rongde LI \\ School of Materials Science and Engineering, Shenyang University of Technology, No. 111, Shenliao Road (west), Shenyang \\ Economic and Technological Development Area, China.
}

(Received on March 26, 2014; accepted on July 1, 2014)

\begin{abstract}
The impact toughness of 400-18L ductile iron (FCD400-18L) was measured by V-notch Charpy impact test at room and low temperatures. SEM and TEM were used to analyze the fracture mechanism. Experimental results show that the energy absorbed by impact test decreases significantly with the decrease of temperature. The fracture properties were measured using instrumented impact testing at temperatures between -80 and $20^{\circ} \mathrm{C}$. The total impact fracture energy, the crack initiation and propagation energy, the dynamic loads and the ductile to brittle temperature were measured. The 400-18L ductile iron exhibited much higher resistance to ductile fracture at high test temperatures, while its resistance to brittle fracture at low test temperatures was reduced. The fracture morphology analysis was discussed in terms of the two fracture types: ductile fracture mechanism upon the BDTT (brittle to ductile transition temperature) and brittle fracture mechanism below the BDTT.
\end{abstract}

KEY WORDS: graphite nodules; brittle to ductile transition; cleavage crack initiation; deformation twins.

\section{Introduction}

Based upon the mechanical properties and quality assurance together with its relatively low cost, the potential use of ductile iron castings would be expected for diverse machine parts with high quality and reliability. ${ }^{1)}$ Due to its excellent ductility and moderate strength (elongation: $18 \%$, ultimate tensile strength: $400 \mathrm{MPa}$ ), 400-18L ductile iron (FCD400$18 \mathrm{~L}$ ) has been widely used in producing some core components of wind power equipment such as the hub of a wind turbine. But long time exposure to cold air brings brittleness to the components. ${ }^{2)}$ Therefore, the low-temperature impact toughness of ductile iron is a critical factor that limits ductile iron's widespread application of wind energy in cold areas.

Charpy V-notch impact tests are widely used to study the fracture properties of ductile irons and, in particular, to define a brittle to ductile transition temperature (BDTT). ${ }^{3)}$ Previous research has shown that the BDTT of $400-18 \mathrm{~L}$ ductile iron is about $-40^{\circ} \mathrm{C}$. ${ }^{4)}$ Charpy impact fracture behavior depends on composition and microstructural parameters like relative amount of ferrite and pearlite, nodularity and nodule count. ${ }^{5)}$ In addition, the impact fracture behavior of ductile cast iron has been investigated that cracks initiate from the surface took place either from nodular graphite or along the grain boundary. ${ }^{6}$ It indicates that the correlation between nodular graphite and ferrite matrix can be assumed to play an important role in the impact fracturing behavior.

* Corresponding author: E-mail: 13840109889@163.com

DOI: http://dx.doi.org/10.2355/isijinternational.54.2309
However, the hypostatic mechanism of the whole impact fracture at different temperatures remains unclear. Therefore, this study aimed to investigate the fracture mechanism during Charpy V-notch impact test under low temperatures.

\section{Experimental}

The initial charge materials were low silicon pig iron and steel scrap. The materials were melted at $1480^{\circ} \mathrm{C}$ in a $50 \mathrm{~kg}$ medium-frequency induction furnace and then poured into a flat bottom ladle at $1400^{\circ} \mathrm{C}$. Pour-over modification was used for spheroidizing of the iron melt (with $1.5 \mathrm{wt} . \% \mathrm{FeSi}$ $\mathrm{CaMgRE}$ as nodulizer), and the inoculation was performed by adding 0.5 wt. $\%$ of a commercial inoculant $(\mathrm{CaBa}-\mathrm{FeSi}$ alloy) before pouring. After de-slagging the melt was poured into a sand mould, and eligible 400-18L ductile cast iron Y-block samples were obtained. The composition of these prepared materials was: C 3.82, Si 2.24, Mn 0.08, P 0.03, S 0.02 (wt.\%).

According to the "Metallic materials- Charpy pendulum impact test- Part 1: Test method (ISO148-1: 2009)",") the impact tests were conducted at different temperatures. The Charpy V-notch specimens are in sizes of $10 \mathrm{~mm} \times 10 \mathrm{~mm} \times$ $55 \mathrm{~mm}$, and the depth of notch is $2 \mathrm{~mm}$. The specimens were put into the attemperator and held for $20 \mathrm{~min}$ at the corresponding temperatures $\left(20^{\circ} \mathrm{C}, 0^{\circ} \mathrm{C},-20^{\circ} \mathrm{C},-40^{\circ} \mathrm{C},-60^{\circ} \mathrm{C}\right.$ and $-80^{\circ} \mathrm{C}$ respectively). The value of impact energy and the whole force- displacement curve were measured using instrumented impact testing machines. A scanning electron microscope (Hitachi S-3400N) was used to observe the microstructures and the fractographs. 


\section{Results and Discussion}

The variation of impact energy with testing temperature for the 400-18L ductile iron is shown in Fig. 1. $\mathrm{KV}_{8}$ indicates the absorbed energy for a $\mathrm{V}$-notch test piece using an $8 \mathrm{~mm}$ striker. As can be seen, the ductile cast iron is showing a decreased value of absorbed energy with decreasing the test temperature. The ductile to brittle transition temperature is below $-45^{\circ} \mathrm{C}$.

Figure 2 shows typical load-deflection curves as derived from the instrumented impact tests for 400-18L ductile iron at different temperatures. As shown, the ductile iron displays a ductile mode of fracture with a total energy of $13.23 \mathrm{~J}$ at $-20^{\circ} \mathrm{C}$, while the ductile iron exhibits a mixed mode of fracture (ductile to brittle transition behavior) with a total energy of $9.79 \mathrm{~J}$ at $-45^{\circ} \mathrm{C}$. However, when temperature decreases to $-80^{\circ} \mathrm{C}$, the fracture shows a fully brittle mode with a total energy of $4.18 \mathrm{~J}$. Figure 2 shows a significant difference between the three curves. In Fig. $2 \mathrm{P}_{\mathrm{m}}$ and $\mathrm{P}_{\mathrm{y}}$ denote maximum dynamic and yield loads, respectively. The area under the curve up to the point of $\mathrm{P}_{\mathrm{m}}$ represents the fracture initiation energy $E_{i}$, while the remaining area represents the fracture propagation energy $\mathrm{E}_{\mathrm{p} .}{ }^{8)}$ Table 1 shows the variation of maximum dynamic and yield loads, total

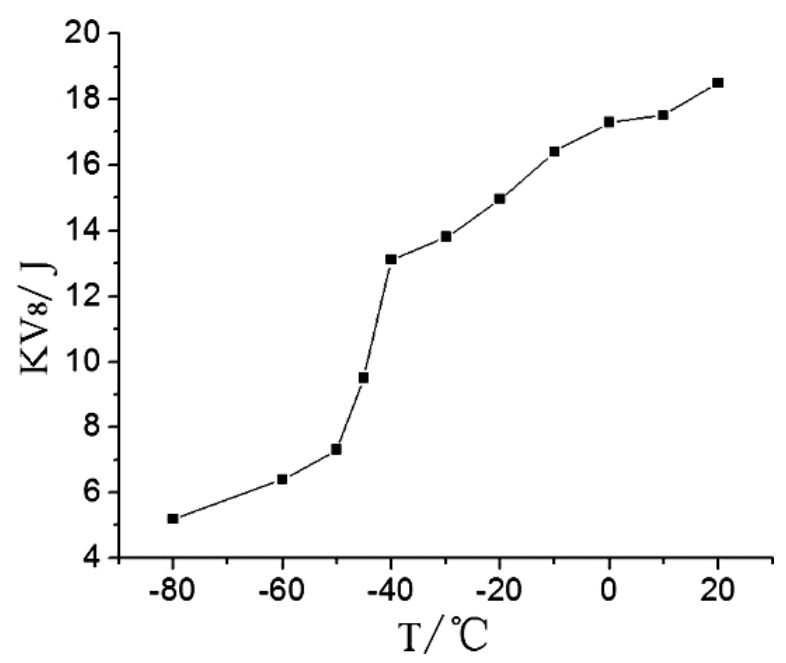

Fig. 1. The impact absorbed energy-temperature curve.

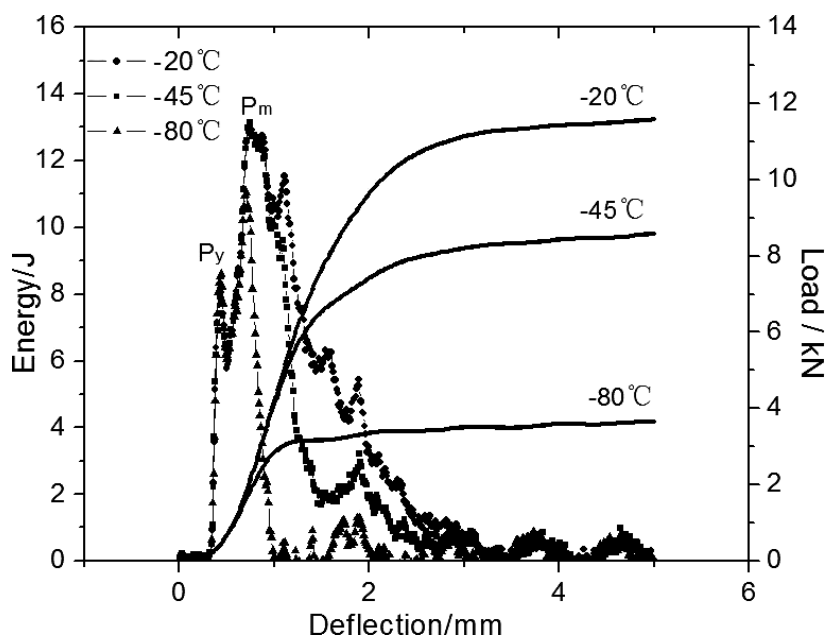

Fig. 2. The impact load-deflection curves.
$\left(E_{t}\right)$ initiation $\left(E_{i}\right)$ and propagation $\left(E_{p}\right)$ energy with test temperature. Both $E_{i}$ and $E_{p}$ are decreased with decreasing the test temperature. It indicates that the crack nucleation and crack propagation become more easily when the temperature decreases. At $-20^{\circ} \mathrm{C}, 400-18 \mathrm{~L}$ ductile iron displayed upper shelf behavior (mostly ductile fracture). The ductile fracture initiation energy, $\mathrm{E}_{\mathrm{i}}$, was about $28 \%$ that of the total fracture energy (3.71 versus $13.23 \mathrm{~J})$. The maximum impact load is $11.38 \mathrm{kN}$ at $-20^{\circ} \mathrm{C}$ and the sudden changed shocking load happened during the crack propagation, which indicates that the internal structure causes a hindering effect on crack propagation. By contrast, the ductile fracture initiation energy value of ductile iron at $-45^{\circ} \mathrm{C}$ was about $33 \%$ that of the total fracture energy $(3.26$ versus $9.79 \mathrm{~J})$. At $-80^{\circ} \mathrm{C}$, the proportion was about $40 \%$. This means that the crack initiation process has consumed less energy than that of the crack propagation process. The line of $-80^{\circ} \mathrm{C}$ in Fig. 2 indicates that cracks propagate rapidly after brittle fracture. It suggests that most of the total fracture energy was expended during the crack propagation process. The fracture propagation energy was reduced obviously for 400-18L ductile iron with the decreasing temperature. In order to clarify the intrinsic fracture mechanism during low-temperature impact test, fracture morphology analysis is very essential.

Figure 3 shows the fracture morphologies of impact specimens at different temperatures. There are obviously a certain amount of dimples around the graphite nodules and some tearing edges along the dimples as shown in Fig. 3(a). The homogeneous dimples are the guarantee of high impact energy $(13.23 \mathrm{~J})$. At $-45^{\circ} \mathrm{C}$ (ductile to brittle transition temperature), the fracture has mixed-rupture characteristics of cleavage facets and dimples. Both dimples and river patterns can be seen in Fig. 3(b). Figure 3(c) shows that the fracture morphology at $-80^{\circ} \mathrm{C}$ is cleavage fracture with amount of river patterns, numerous of graphite nodules were brushed off during the impact process. As the testing temperature decreases, the number of dimples decreases; while the proportion of cleavage fracture increases. It is clear that a significant deterioration of crack propagation resistance occurs with the decrease in temperature. Based on the earlier investigations, the matrix morphologies actually play an important role in causing deterioration in fracture resistance. In addition, it can be deduced that the crack propagation resistance should be correlated to the existence of graphite nodules.

Specimens tested at $-20^{\circ} \mathrm{C}$ temperature suggest fracture proceeding by void coalescence manner (ductile fracture mode). The fracture surface is characterized by a mixture of large cavities containing graphite nodules and smaller voids on the grain boundaries (Figs. 4(a) and 4(b)). Figure 4(a) shows the structure character of a dimple at magnification of 1000X. The graphite nodule locates in the center of the

Table 1. Variation of maximum dynamic $\left(\mathrm{P}_{\mathrm{m}}\right)$ and yield loads $\left(\mathrm{P}_{\mathrm{y}}\right)$, total $\left(\mathrm{E}_{\mathrm{t}}\right)$ initiation $\left(\mathrm{E}_{\mathrm{i}}\right)$ and propagation $\left(\mathrm{E}_{\mathrm{p}}\right)$ energy with test temperature.

\begin{tabular}{rrrrrr}
\hline $\mathrm{T} /{ }^{\circ} \mathrm{C}$ & $\mathrm{P}_{\mathrm{m}} / \mathrm{kN}$ & $\mathrm{P}_{\mathrm{y}} / \mathrm{kN}$ & $\mathrm{E}_{\mathrm{i}} / \mathrm{J}$ & $\mathrm{E}_{\mathrm{p}} / \mathrm{J}$ & $\mathrm{E}_{\mathrm{t}} / \mathrm{J}$ \\
\hline-20 & 11.38 & 7.53 & 3.71 & 9.52 & 13.23 \\
-45 & 11.16 & 7.15 & 3.26 & 6.53 & 9.79 \\
-80 & 9.65 & 6.92 & 1.67 & 2.51 & 4.18 \\
\hline
\end{tabular}



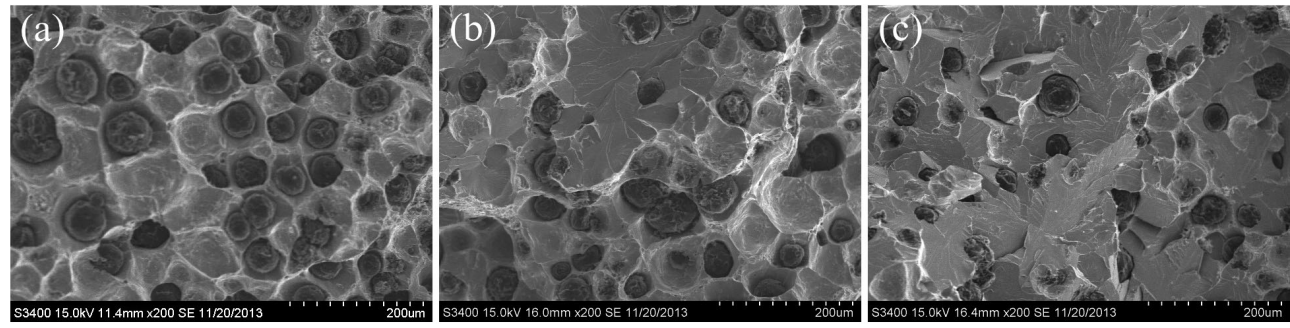

Fig. 3. The fracture morphologies of impact specimens at different temperatures: (a) $-20^{\circ} \mathrm{C}$; (b) $-45^{\circ} \mathrm{C}$; (c) $-80^{\circ} \mathrm{C}$.
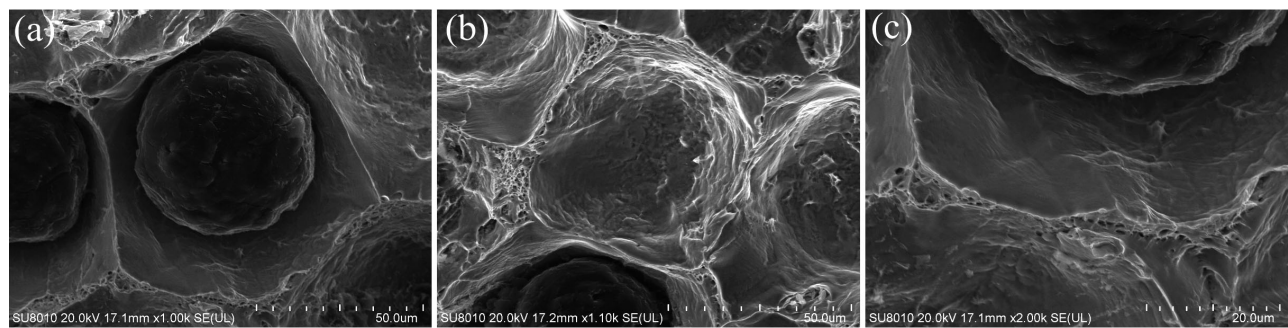

Fig. 4. The fracture morphologies of impact specimens at $-20^{\circ} \mathrm{C}$.

(a)

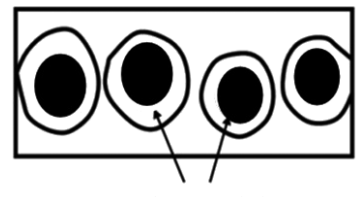

graphite nodules (b)

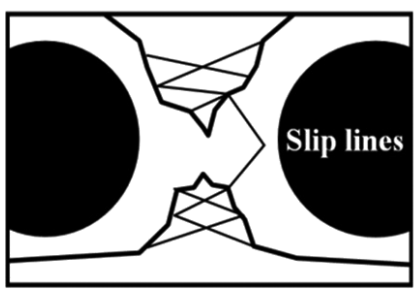

(c)

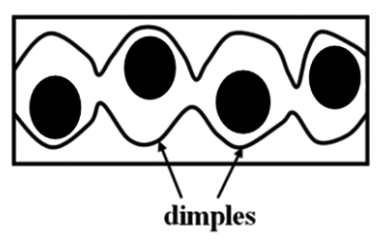

Fig. 5. Model for ductile fracture.

dimple. In the vicinity of the graphite nodule, the wider areas of the ferrite phase are considerably deformed. Slip lines are mainly distributed in the edge of the dimples Fig. 4(c). Thus, the fraction of dimples depends on the number of graphite nodules. The micromechanism operative during ductile fracture involves crack initiation through nucleation and growth of voids around graphite nodules and inclusions followed by crack propagation through plastic deformation of the matrix. ${ }^{9)}$

On the basis of results and discussion in the preceding sections, the fracture in ductile iron under impact loading at $-20^{\circ} \mathrm{C}$ was discussed from macroscopic and microscopic viewpoints, and then a model for the fracture is proposed, as shown in Fig. 5. The relationship between the graphite nodules and ferrite matrix under impact load at $-20^{\circ} \mathrm{C}$ temperature is illustrated. When an impact load is applied to a ductile iron material, separations are first caused along the interfaces between graphite nodules and their matrices immediately after a deformation exceeding the elastic limit, as actually observed in Fig. 5(a). But the stress may not perfectly be relaxed only by such separations, and more stress is induced in the matrix regions, which lead to a fracture on the slip bands (Fig. 5(b)). As a result, the cracks nucleated in graphite-matrix boundaries are connected through adjacent interface separations, and the ductile iron material is finally fractured, as shown in Fig. 5(c).

When temperature decreases to $-45^{\circ} \mathrm{C}$, about half of fracture represents brittle fracture occurring along crystallo- graphic planes. Figures 6(a) and 6(a') show the symmetric fracture morphologies of impact specimens at $-45^{\circ} \mathrm{C}$, complex severe deformations are occurred around the irregular graphite nodule. These are indications of the absorption of energy by local deformation. In Figs. 6(b) and 6(b'), wispy slip lines are distributed uniformly in the matrix around the graphite nodule. They spread around and extend to the graphite pits or free surfaces. This indicates that the effect of stress concentration around nodular graphite can be assumed to be responsible for cleavage fractures.

The most remarkable characteristic of fracture at low temperature is flat facets which exhibit "river marking" (Fig. 7). The river markings are caused by the crack moving through the crystal along a number of parallel planes. ${ }^{10)}$ According to the morphology and distribution of slip bands on cleavage facets (Fig. 7(a)), the slip bands on fracture surfaces in some cases ran through the grain boundary, whilst in other cases they were blocked. The river patterns in Fig. 7(b) represent an interesting case in which slip dislocations were stopped on the grain boundary.

The low temperature effect on crack propagation should be considered closely related to dislocation movement. According to Keh, similar local deflection of grain boundary was associated with high dislocation density and explained via the interaction of slip with the grain boundary during its growth. ${ }^{11)}$ It can therefore be concluded that our experimental results indicating the possibility of dislocations piling up on the grain boundary at $-80^{\circ} \mathrm{C}(\mathbf{F i g . ~ 8}(\mathrm{b}))$, are in agreement 

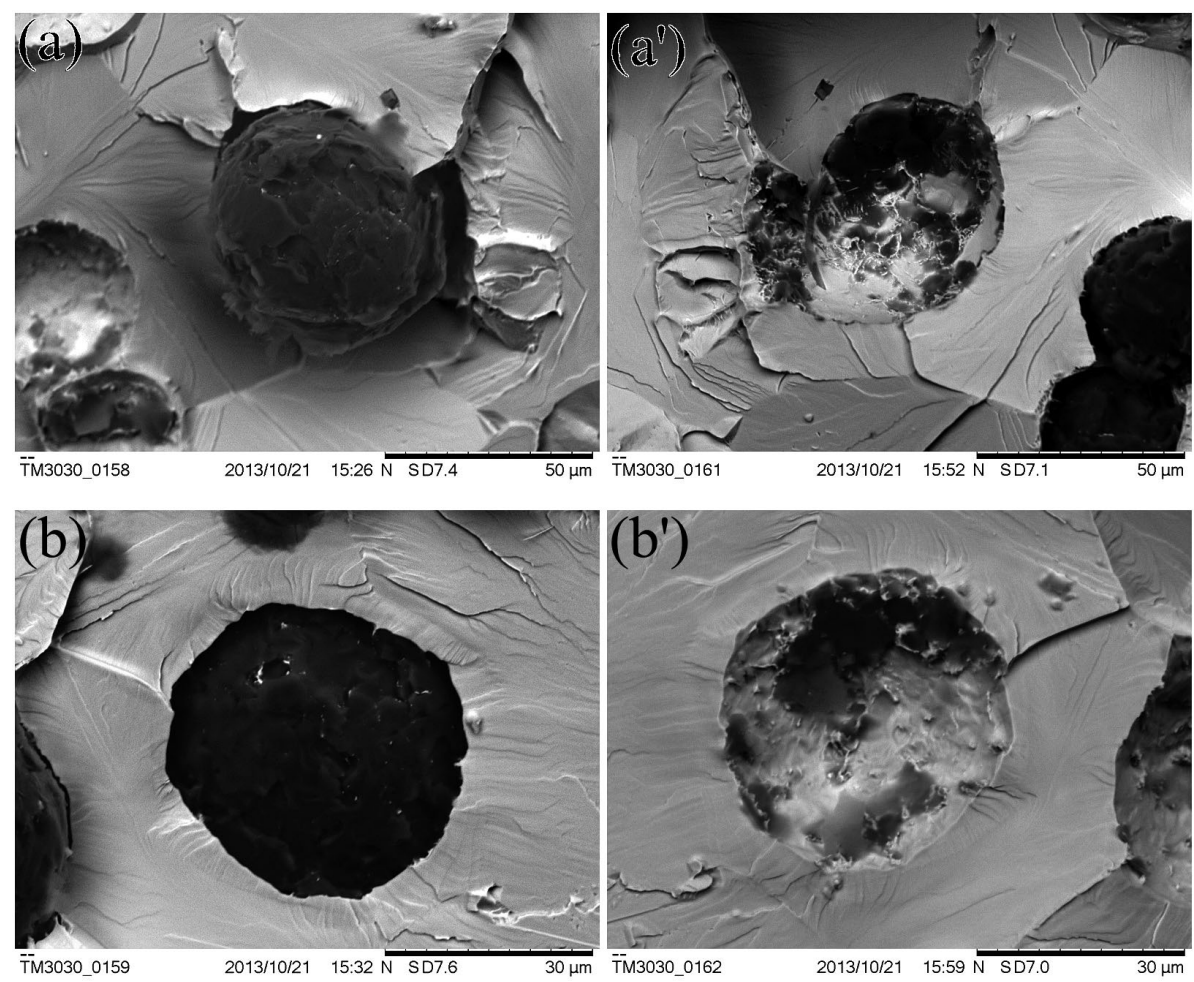

Fig. 6. The symmetric fracture morphologies of impact specimens at $-45^{\circ} \mathrm{C}$.
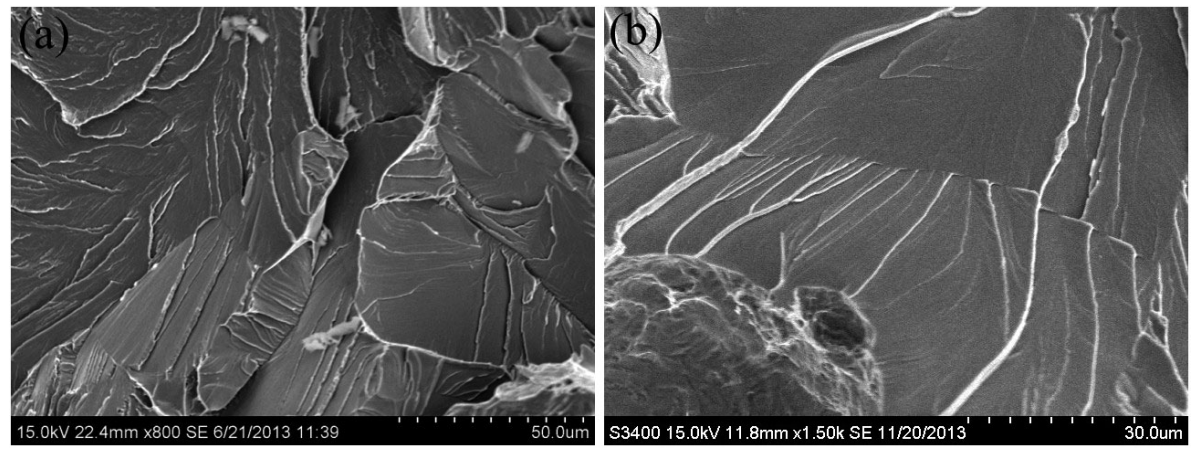

Fig. 7. Cleavage fracture in the grain boundary at $-80^{\circ} \mathrm{C}$.

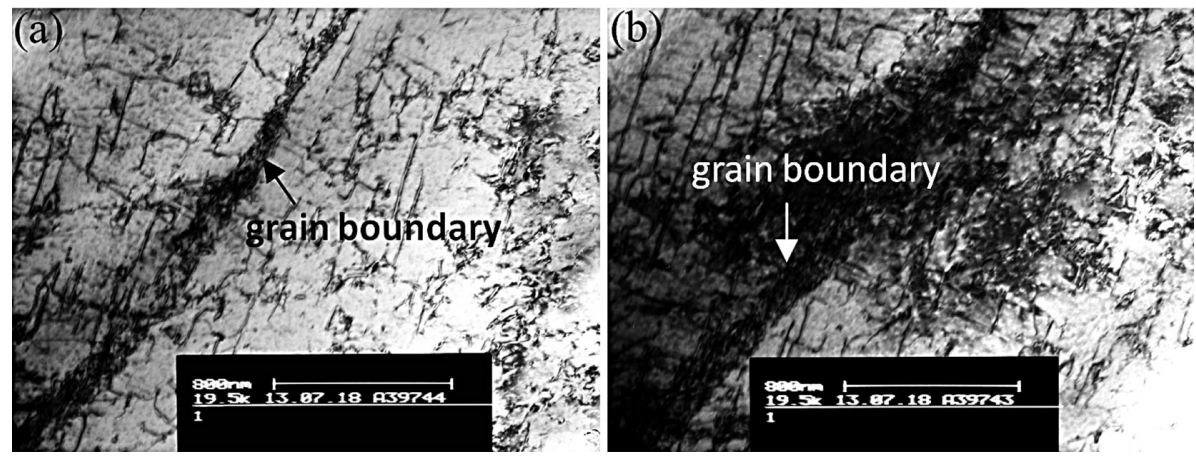

Fig. 8. Dislocation structures close to the fracture surface at different temperatures: (a) $-20^{\circ} \mathrm{C}$; (b) $-80^{\circ} \mathrm{C}$.

with the reference data. Dislocations piled up in a sufficiently large amount against the grain boundary can lead to initiation of cleavage fracture.

In addition to the river pattern fracture morphology, the occurrence of deformation twins was observed under the BDTT (Figs. 9(a) and 9(b)). Based on the results of the impact test and the microscopic observations of ferritic matrix, it can be summarized that in the low range of testing temperatures, cleavage fracture was always associated with deformation twinning. Deformation twinning thus very likely occurs at temperatures lower than the BDTT. On the other hand, the deformation twins were not observed in the test specimens with entirely ductile fracture.

As above mentioned analysis, it can be summarized that 

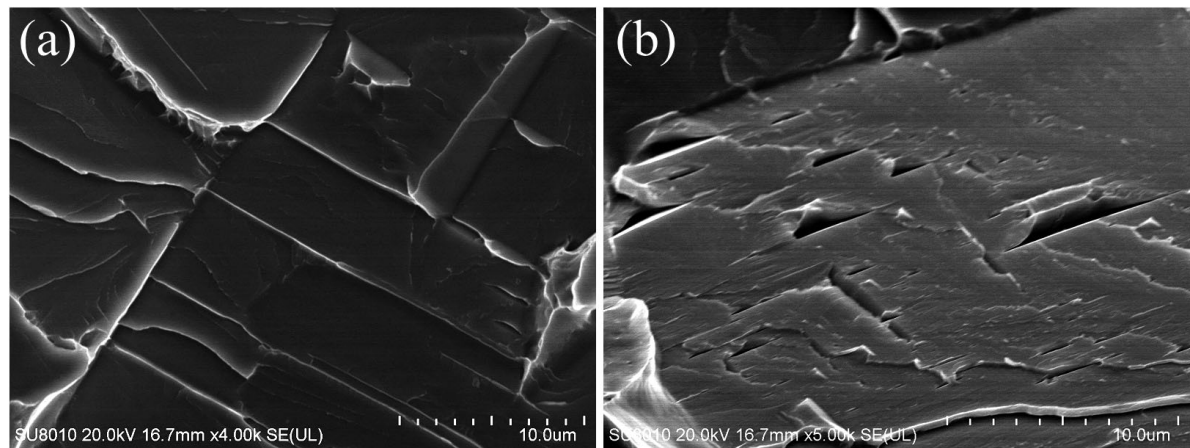

Fig. 9. Deformation twins at $-80^{\circ} \mathrm{C}$ : (a) twins; (b) cleavage tongues.

cleavage fracture of ductile iron is associated with deformation twining under BDTT. The explanation as to why twinning is prevalent at low temperatures is that an enclosed twin must always have some accommodating slip near its edge due to high stress concentration near the edge. The applied stress needed to propagate the twin will increase when the slip activity near the edge increase. Since dislocation glide is thermally activated, therefore at low temperatures accommodating slip activity is low, leading to a lower stress needed to propagate the twin. ${ }^{12,13)}$ The decreased temperature will also support the piling up of dislocations in front of the twin boundary. ${ }^{14)}$ In conclusion, it indicates that deformation twinning could possibly play a significant role in the BDT of $400-18 \mathrm{~L}$ ductile iron.

\section{Summary}

The cleavage fracture resistance of 400-18L ductile iron is reduced with the decrease of impact temperatures. The crack initiation process has consumed less energy than that of the crack propagation process. Most of the total fracture energy was expended during the crack propagation process. Upon the BDTT, the micromechanism operative during ductile fracture involves crack initiation through nucleation and growth of voids around graphite nodules and inclusions followed by crack propagation through plastic deformation of the matrix. The cracks nucleate in graphite-matrix boundaries are connected through adjacent interface separations, and the ductile iron material is finally fractured. Below the
BDTT, dislocations piled up in a sufficiently large amount against the grain boundary can lead to initiation of cleavage fracture. Deformation twinning could possibly play a significant role in the BDT of 400-18L ductile iron.

\section{Ackowlegement}

This study was financially supported by the National Natural Science Foundation of China (No. 51274142).

\section{REFERENCES}

1) Y. Iwabuchi, H. Narita and O. Tsumura: Res. Rep., Kushiro National College, 37 (2003), 1.

2) G. S. Cho, K. H. Choe and K. W. Lee: J. Mater. Sci. Tech., 23 (2007), 97.

3) A. Pineau: Int. J. Fracture, 138 (2006), 139.

4) O. Yanagisawa and T. S. Lui: Trans. Jpn. Inst. Met., 24 (1983), 858

5) P. J. J. Ratto, A. F. Ansaldi, V. E. Fierro, F. R. Agüera, H. N. Alvarez Villar and J. A. Sikora: ISIJ Int., 41 (2001), 372.

6) Z. Yajima, Y. Kishi, K. Shimizu, H. Mochizuki and T. Yoshida: Mater. Trans. JIM, 47 (2006), 82.

7) EN Metallic Materials - Charpy Pendulum Impact Test-Part1, Test Method (ISO 148-1-2009), International Organization for Standardization, Switzerland, (2009).

8) O. H. Ibrahim and E. S. Elshazly: J. Mater. Eng. Perform, 22 (2013), 584.

9) P. Q. Dai, Z. R. He, C. M. Zheng and Z. Y. Mao: Mater. Sci. Eng. A, 319-321 (2001), 531.

10) C. R. Brooks: Failure Analysis of Engineering Materials, Machine Press, Beijing, (2003), 256.

11) J. Syarif, T. Tsuchiyama and S. Takaki: ISIJ Int., 43 (2003), 1100.

12) M. Tanaka, T. Onomoto, T. Tsuchiyama and K. Higashida: ISIJ Int., 52 (2012), 915.

13) J. Bošanský and T. Šmida: Mater. Sci. Eng. A, 323 (2002), 198.

14) T. Šmida and J. Bošanský: Mater. Sci. Eng. A, 287 (2000), 107. 